\title{
Oblique odontoid fracture. Case report and review of the literature
}

\author{
S Katoh MD, W S El Masry MB BCh FRCSEd*, C G Inman MB ChB FRCSEd \\ The Midlands Centre for Spinal Injuries, Robert Jones and Agnes Hunt Orthopaedic and \\ District Hospital, Oswestry, Shropshire SY10 7AG, England
}

The case of a 89 year old patient with an oblique odontoid fracture is reported. The fracture was oblique extending from the middle of the anterior aspect of the dens to the posterior junction with the body. There was also posterior displacement. This fracture was different from the previously reported two vertical fractures of the odontoid. The possible mechanism of the lesion, and the management of this patient are discussed.

Keywords: odontoid process; oblique fracture.

\section{Introduction}

The classification of odontoid fractures advocated by Anderson and D'Alonzo ${ }^{1}$ has been widely accepted. This identifies three main types of the fracture. In that classification, type $I$ is an oblique fracture of the tip of the dens, type II is a fracture of the junction of the dens with the central body of the axis, and type III is a fracture in which the fracture line extends downward into the cancellous portion of the body of the axis. Difficulties, however, have been encountered with some odontoid fractures that could not be classified using this system. We report here such a fracture which was oblique and which extended in an anteroposterior direction.

\section{Case report}

An 89 year old man had a fall in the toilet, striking his forehead and nose, and experiencing pain in his neck. Physical examination revealed tenderness over the upper cervical spine but without any neurological deficit. Cervical plain lateral radiographs demonstrated an oblique fracture in a frontal plane extending from the middle of the anterior aspect of the odontoid process to the posterior junction between its posterior border and the body of axis. There was a significant caudal and posterior displacement of the proximal fragment (Fig 1). A computerised tomography (CT) scan demonstrated this oblique fracture clearly in axial and

\footnotetext{
${ }^{*}$ Correspondence
}

saggital views (Fig 2). The patient was treated nonsurgically with 19 days of bedrest and cervical bracing for a further 9 weeks (Philadelphia collar for 3 weeks and soft collar for 6 weeks). His general condition and age suggested that there would be a high risk to his life from surgery. He developed hyponatremia and was severely confused for 5 days after injury which made it difficult to retain him in bed. At 10 months follow up, he had normal neurology, full orientation and full ambulation. Although the range of movements of his neck was still restricted, he did not complain of any pain in his neck. The dynamic views of lateral radiographs at this time showed no movement at the site of the fracture, and a CT scan revealed bony union (Fig 3).

\section{Discussion}

In the last 15 years, 57 patients with odontoid fractures were treated in our centre. One of these fractures was classified as type I, 38 type II and 16 type III. Two fractures could not be classified according to the scheme of Anderson and D'Alonzo. ${ }^{1}$ One of these patients had a comminution of the odontoid process, although from the lateral radiographs alone the fracture would be classified as type II.

Odontoid fractures with vertically orientated fracture lines are rare and difficult to classify according to the description and scheme of Anderson and D'Alonzo. There are, to our knowledge, two case reports in the literature. ${ }^{2.3}$ The patients were young (21 and 18 years old) and the displacements 


\section{a}

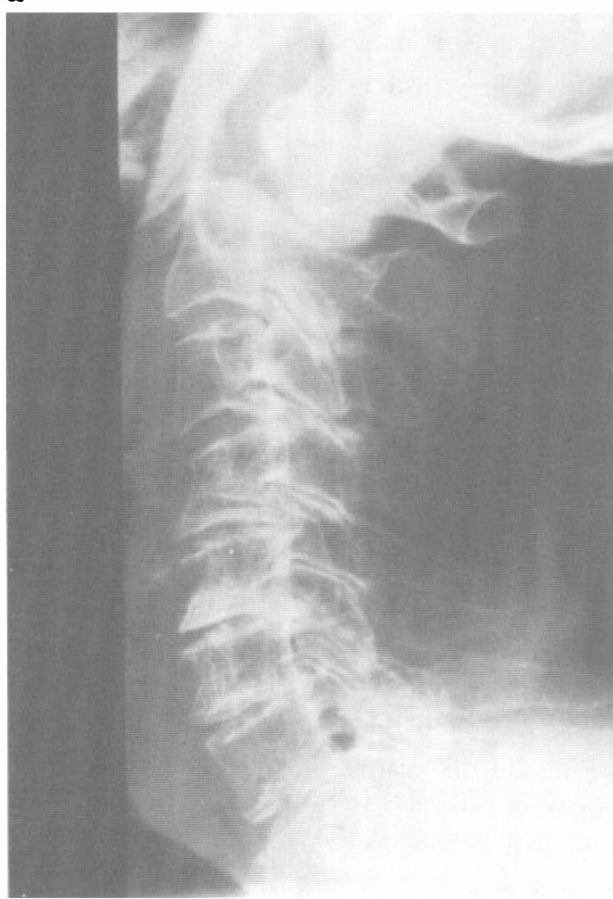

b

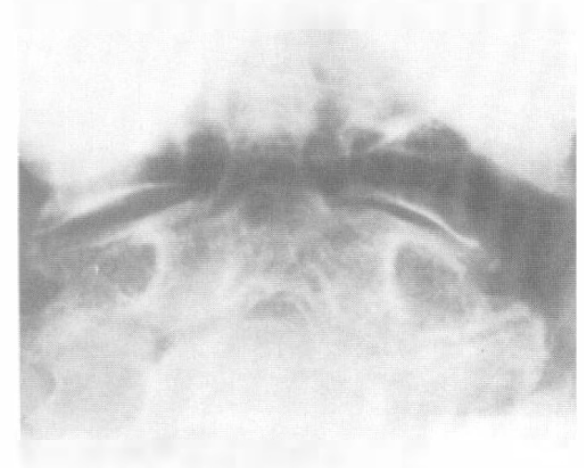

Figure 1 (a) Lateral plain $\mathrm{x}$-ray showing oblique fracture of odontoid process with posterior and caudal displacement of the proximal fragment. (b) Open mouth view showing only lucent fracture line in the base of the odontoid process.

\section{a}

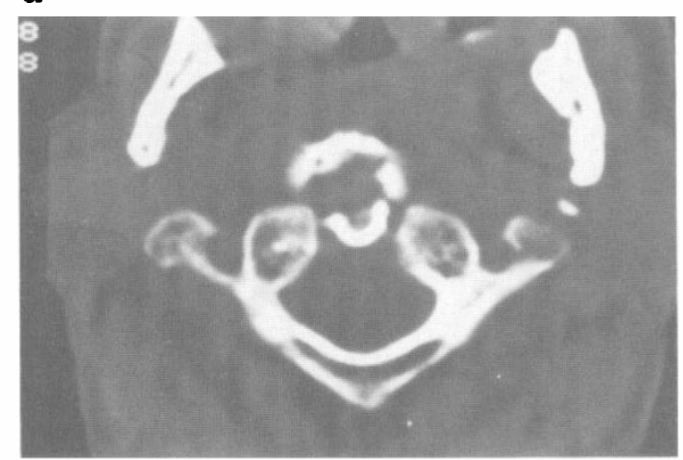

b

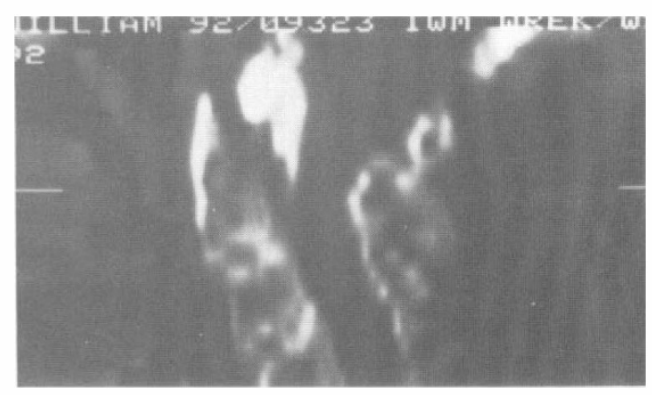

Figure.2 (a) Axial computerised tomography (CT) scan on admission showing the fracture in a frontal plane. (b) Saggital reconstruction of the CT scan demonstrating the oblique fracture.

of the fractures were minimal. Neither fracture could be detected by plain lateral radiography but both were shown on $\mathrm{CT}$ scan. The fracture lines extended from the top of the odontoid process to its junction with the body of the axis. Bergenheim and
Forssell ${ }^{2}$ described the mechanism of injury in their report and suggested that there was a vertical force from the head downward and backward causing the anterior edge of the foramen magnum to strike the odontoid process in the axial direction. The associ- 
a

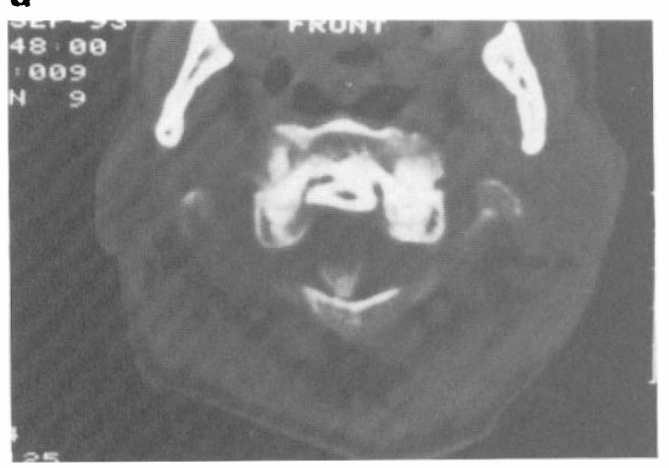

b

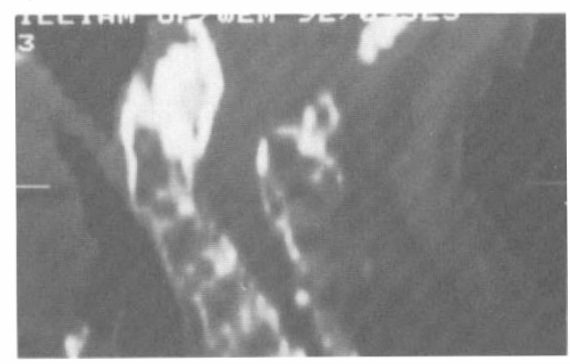

Figure 3 (a) Axial CT scan at 10 months follow up demonstrating bridging callus between the segments of the fracture. (b) Saggital reconstruction of the CT scan showing the union of the fracture in the same position as that in the initial examination.

ated fracture of the ring of the atlas may have supported this mechanism.

Posterior displacement of the fracture is common in type II odontoid fractures $(39 \%$ to $63 \%) .4 .5$ On the other hand, posterior displacement is uncommon in type III odontoid fractures. Clark and White ${ }^{4}$ found only two out of 19 patients with this type of injury in their series. We found another two patients with posterior displacement of the odontoid fracture in a population of 17 patients with a type III fracture, which is similar to the incidence documented by Clark and White. ${ }^{4}$ The fracture lines of these two patients with type III fracture had a different direction from Anderson and D'Alonzo's original description. ${ }^{1}$

The fracture line of our patient extended from the anterior aspect of the odontoid process at the level of the lower end of anterior arch of atlas to the posterior junction with the body of the axis. From the site of the frontal and facial lacerations and the direction of the fracture line, we assumed that the force vector pushed the head backward and downward and that the anterior arch of the atlas hit the odontoid process. To our knowledge, this oblique type of odontoid fracture has not previously been documented either clinically or experimentally. ${ }^{6.7}$

The treatment of elderly patients with odontoid fractures is controversial. Hanigan et $a l^{8}$ reported a high mortality rate $(26.3 \%)$, stating that fibrous union with stability may be a sufficient goal of treatment in elderly patients with odontoid fractures. In the present case, we employed conservative treatment because of the general condition and age of the patient as well as a wide surface area between the two segments of the fracture. At 10 months follow up, he did not complain of neck pain, and radiographic examinations revealed bony union.

\section{Acknowledgement}

The authors wish to thank Dr I McCall and Dr V Pullicino for their kind assistance.

\section{References}

1 Anderson LD, D'Alonzo RT (1974) Fractures of the odontoid process of the axis. J Bone Joint Surg 56A: 1663-1674.

2 Bergenheim AT, Forssell A (1991) Vertical odontoid fracture. Case report. J Neurosurg 74: 665-667.

3 Johnson JE, Yang PJ, Seeger JF, Iacono RP (1986) Vertical fracture of the odontoid: CT diagnosis. J Comput Assist Tomogr 10: 311-312.

4 Clark CR, White AA III (1985) Fractures of the dens. A multicenter study. J Bone Joint Surg 67A: 1340-1348. 
5 Levine AM, Edwards CC (1986) Treatment of injuries in the C1-C2 complex. Orthop Clin North Am 17: $31-44$.

6 Althoff B, Goldie IF, Romanus B (1979) Experimental fracture of the odontoid process of the axis. Acta Orthop Scand Suppl 177: 11-49.

7 Mouradian WH, Fietti VG Jr, Cochran GVB, Fielding JW, Young J (1978) Fractures of the odontoid: a laboratory and clinical study of mechanisms. Orthop Clin North Am 9: 985-1001.

8 Hanigan WC, Powell FC, Elwood PW, Henderson JP (1993) Odontoid fractures in elderly patients. J Neurosurg 78: 32-35. 